\title{
Unexpected differences between thermal and photoinitiated cationic curing of a diglycidyl ether of bisphenol A modified with a multiarm star poly(styrene)-b-poly(e-caprolactone) polymer
}

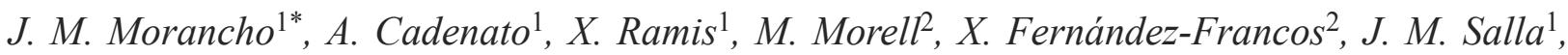 \\ A. Serra ${ }^{2}$ \\ ${ }^{1}$ Thermodynamics Laboratory, Heat Engines Departament, ETSEIB, Universitat Politècnica de Catalunya, Av. Diagonal \\ 647, 08028 Barcelona, Spain \\ ${ }^{2}$ Department of Analytical and Organic Chemistry, Universitat Rovira i Virgili, C/ Marcel·lí Domingo s/n, 43007 \\ Tarragona, Spain
}

Received 4 January 2013; accepted in revised form 18 March 2013

\begin{abstract}
The effect of adding a multiarm star poly(styrene)- $b$-poly(e-caprolactone) polymer on the cationic thermal and photoinitiated curing of diglycidyl ether of bisphenol A was studied. This star-polymer decelerated the thermal curing of diglycidyl ether of bisphenol A and modified the final structure of the epoxy matrix. The photocuring was influenced significantly by the addition of the multiarm star. When the proportion of this modifier added was $5 \%$, much more time was necessary for complete photocuring $\left(160 \mathrm{~min}\right.$ at $\left.40^{\circ} \mathrm{C}\right)$. In the presence of $10 \%$ of modifier, the degree of photocuring reached was very low $\left(0.196\right.$ at $\left.120^{\circ} \mathrm{C}\right)$. A subsequent thermal post-curing was necessary to cure completely the system. During photocuring in presence of poly(styrene)- $b$-poly( $\varepsilon$-caprolactone), the formation of dormant species, which are reactivated when the temperature increases, takes places. The kinetics of the thermal curing and the photocuring was analyzed using an isoconversional method due to the complexity of the reactive process. Applying this method, it has been confirmed the dependence of activation energy on the degree of conversion. The fracture morphology analyzed by scanning electron microscopy exhibited a second phase originated during photocuring by the presence of the modifier.
\end{abstract}

Keywords: thermosetting resins, multiarm star polymer, thermal curing, photocuring, kinetics

\section{Introduction}

Epoxy resins are used in a wide range of applications, such as adhesives, coatings, castings, electrical and electronic materials, encapsulation of semiconductor devices, matrix material for composites, structural components [1-9] and cryogenic engineering [10-12]. Epoxy resins have good mechanical and chemical properties, adhesion, thermal stability and electrical characteristics. However, they are inherently brittle due to their relatively rigid molecular structure, which limits their use. In coatings, the curing shrinkage can cause serious problems due to the generation of microvoids and microcracks, deformation and loss of adhesion. Then the protection capability and durability of the coating are reduced, which allows corrosion of the substrate as a result of the penetration of moisture [13]. In order to increase the toughness of the epoxy resins different modifiers can be added to them, like rubber and thermoplastic, but they always limit the processability of the resin systems [14-19].

\footnotetext{
${ }^{*}$ Corresponding author, e-mail: morancho@mmt.upc.edu (C) BME-PT
} 
Hyperbranched polymers (HBP) are a new family of polymeric modifiers that can be added to epoxy resins to increase their toughness without compromising the processability due to their highly branched dendritic structure [20]. The main advantages of HBPs are their low viscosity compared with their linear counterparts, the possibility of tailoring their core and branches structure and the functionalization of the end groups so that they can be compatible with the surrounding matrix [21]. HBPs can also reduce the shrinkage of the resin during the curing process [22] and the internal stresses [6]. The glass transition of the epoxy resin can be reduced by HBPs [21] or left unaltered [6], depending on different factors, such as the formation of a second phase during curing, the glass transition temperature of HBP and the interactions between modifier and epoxy matrix. In previous works, the influence of some HBPs in the thermal curing and the photocuring cationically initiated of a diglycidyl ether of bisphenol A (DGEBA) has been studied [23-25].

In addition to HBPs, multiarm star polymers can also be considered as a new class of reactive modifiers for epoxy resins. In this paper, the influence of a multiarm star polymer based on hyperbranched poly(styrene)- $b$-poly( $\varepsilon$-caprolactone) on the cationic thermal curing and on the cationic photocuring of an epoxy resin is reported. This polymer was previously synthesized and used as a modifier in the thermal anionic curing of DGEBA [26]. Hyperbranched poly(styrene)- $b$-poly( $\varepsilon$-caprolactone) showed a slightly decelerative effect on the curing, a homogeneous nanograined morphology and good processability when was used as reactive modifier of epoxy thermosets cured in the presence of tertiary amine. In another previous work, the influence of two multiarm star polymers, based on hyperbranched poly (glycidol)- $b$-poly( $\varepsilon$-caprolactone) on the cationic thermal curing and the cationic photocuring of the same epoxy resin was studied [27]. These polymers decelerated the thermal curing and the photocuring, but to a lesser extent than the poly(styrene)- $b$-poly ( $\varepsilon$-caprolactone) polymer, studied in this work.

In addition to the kinetics of thermal and UVinduced curing and thermal properties of poly (styrene)- $b$-poly( $\varepsilon$-caprolactone)/DGEBA mixtures, the potential capacity of the star-like topology to enhance epoxy toughness is also discussed.

\section{Experimental}

\subsection{Materials}

DGEBA with an epoxy equivalent of $187 \mathrm{~g} / \mathrm{ee}$ (EPIKOTE 828, Hexion Specialty Chemicals B.V., Hoogvliet, Netherlands) was dried in vacuum before use. A multiarm star poly(styrene)- $b$-poly( $\varepsilon$-caprolactone) (from now on PS-10) with 60 arms per molecule, a degree of polymerization of the poly $(\varepsilon-$ caprolactone) arms of 10 and an average molecular weight in number of $76,200 \mathrm{~g} / \mathrm{mol}$ was synthesized by us following a reported procedure [26]. Figure 1 shows the idealized chemical structure of this polymer. Ytterbium triflate $\left(\mathrm{Yb}(\mathrm{OTf})_{3}\right)$ (Aldrich, St. Louis, Missouri, USA) has been used as thermal cationic initiator. The photoinitiator used is CYRACURE UVI-6976 (triarylsulfonium hexafluoroantimonate, $50 \mathrm{wt} \%$ in propylene carbonate) and was received from Dow Chemical Company (Midland, Michigan, USA).

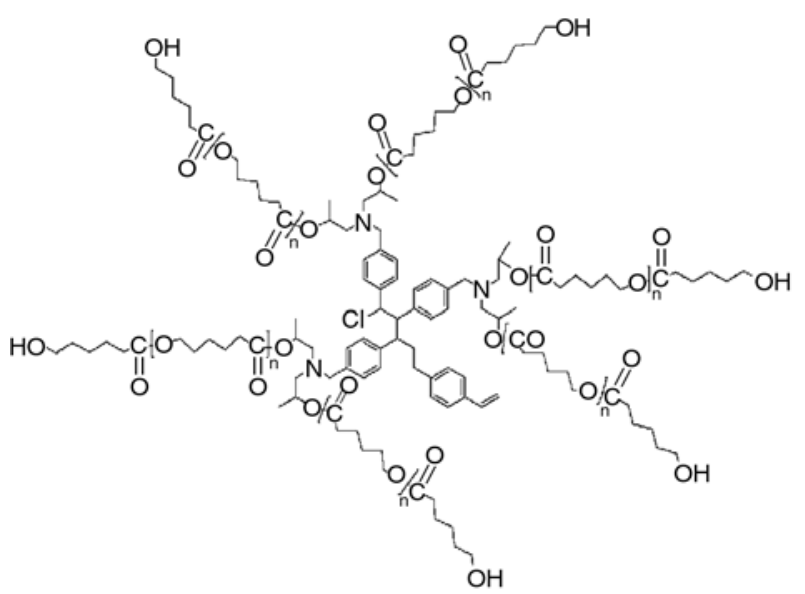

Figure 1. Idealized chemical structure of the multi arm star poly(styrene)- $b$-poly( $\varepsilon$-caprolactone)

\subsection{Preparation of curing formulations}

The mixtures of liquid DGEBA and solid star polymer were prepared by mixing and heating the desired quantities of these substances using a hot air blower and vigorous stirring. In the thermally curable samples, $1 \mathrm{phr}$ (parts of initiator per 100 parts of resin) of the thermal initiator was added to the mixtures at room temperature and they were stirred and kept at $-18^{\circ} \mathrm{C}$ to prevent polymerization. In the photocurable samples of neat DGEBA, $2 \mathrm{phr}$ of CYRACURE UVI-6976 was added (because the concentration of photoinitiator was 50\% in weight in the CYRACURE UVI-6976 solution, 2 phr of this solution was needed for a concentration of $1 \mathrm{phr}$ of photoinitiator in the 
reactive mixture) and they were stirred and kept in the dark at $-18^{\circ} \mathrm{C}$. In the photocurable samples of DGEBA with different proportions of PS-10, $4 \mathrm{phr}$ of CYRACURE UVI-6976 was added (the concentration of the photoinitiator in the reactive mixture was $2 \mathrm{phr})$.

\subsection{Thermal curing}

The thermally curable samples were cured at different heating rates $\left(2.5,5,7.5,10\right.$ and $\left.15^{\circ} \mathrm{C} / \mathrm{min}\right)$ in a Mettler 822e calorimeter (Mettler-Toledo, Schwerzenbach, Switzerland) under a nitrogen atmosphere. The dynamic scans were performed from 0 to $250^{\circ} \mathrm{C}$ when the system was neat DGEBA. But when a proportion of 5 or $10 \%$ of PS-10 was added to DGEBA the dynamic scans were performed from 0 to $330^{\circ} \mathrm{C}$ at $15^{\circ} \mathrm{C} / \mathrm{min}$ and from 0 to $300^{\circ} \mathrm{C}$ at the other heating rates. The ultimate glass transition temperature of the cured materials $\left(T_{\mathrm{g}_{0}}\right)$ was determined on the basis of a second dynamic run from 100 to $250^{\circ} \mathrm{C}$ at $10^{\circ} \mathrm{C} / \mathrm{min}$, as the temperature of the half-way point of the jump in the heat capacity when the material changed from glassy to the rubbery state under $\mathrm{N}_{2}$ atmosphere and the error is estimated to be approximately $\pm 1^{\circ} \mathrm{C}$.

\subsection{Photocuring}

The photocurable samples were photocured at different temperatures, in a Mettler DSC-821e (Mettler-Toledo, Schwerzenbach, Switzerland) calorimeter appropriately modified with a Hamamatsu Lightningcure LC5 (Hg-Xe lamp) (Hamamatsu Photonics K.K., Hamamatsu City, Japan) with two beams, one for the sample side and the other for the reference side. Samples of ca. $5 \mathrm{mg}$ were cured in open aluminium pans in a nitrogen atmosphere. Two scans were performed on each sample to subtract the thermal effect of UV irradiation from the photocuring experiment, each one consisting of four minutes of temperature conditioning, a period of time of irradiation and finally four minutes more without UV light. The light intensity used was calculated by irradiation of graphite-filled plans on only the sample side. The period of time of irradiation depended on the analyzed system. For the neat DGEBA, it was $30 \mathrm{~min}$. For the DGEBA modified with $5 \%$ of PS-10 this period of time depended on temperature. This period changed between $80 \mathrm{~min}$ (at $120^{\circ} \mathrm{C}$ ) and $160 \mathrm{~min}\left(\right.$ at $\left.40^{\circ} \mathrm{C}\right)$. These different periods of time were necessary to ensure a complete photocuring process. Dynamic postcuring experiments were carried out in the same DSC, without irradiation, from 30 to $250^{\circ} \mathrm{C}$ at $10^{\circ} \mathrm{C} / \mathrm{min}$ to determine the residual heat. After this, a second dynamic run was carried out to determine $T_{\mathrm{g} \infty}$.

When DGEBA was modified with $10 \%$ of PS- 10 the system was photocured at $120^{\circ} \mathrm{C}$ for $30 \mathrm{~min}$, and after that, it was thermally postcured at different heating rates from 30 to $300^{\circ} \mathrm{C}$, with the exception of the heating rate of $15^{\circ} \mathrm{C} / \mathrm{min}$, where the final temperature was $330^{\circ} \mathrm{C}$.

\subsection{SEM (Scanning Electron Microscopy)}

Some samples were photocured isothermally in a polypropylene mould $\left(2.35 \times 1.2 \times 0.3 \mathrm{~cm}^{3}\right.$, with a thickness of $0.5 \mathrm{~mm}$ ) at room temperature. Each side of the sample was irradiated for 15 min with a monochromatic UV lamp of $365 \mathrm{~nm}$ wavelength and $4 \mathrm{~mW} / \mathrm{cm}^{2}$ of intensity. They were subsequently postcured at $180^{\circ} \mathrm{C}$ for two hours, cooled in liquid nitrogen and fractured. The fracture surface of these samples was coated with a conductive gold layer and then examined with a JEOL JSM-6400 SEM (JEOL Ltd., Tokyo, Japan), with a magnification of 20,000 .

\section{Theory}

In the thermal curing processes the degree of conversion $(\alpha)$ was calculated according to Equation (1):

$\alpha=\frac{\Delta h_{\mathrm{T}}}{\Delta h_{\mathrm{dyn}}}$

where $\Delta h_{\mathrm{T}}$ is the heat released up to a temperature $T$, obtained by integration of the calorimetric signal up to that temperature and $\Delta h_{\mathrm{dyn}}$ is the total reaction heat of the experiment, associated with complete conversion of all reactive groups. Cure completion was confirmed by FTIR of the samples after dynamic curing.

The rate of conversion $(\mathrm{d} \alpha / \mathrm{d} t)$ is proportional to a function of the degree of conversion $(f(\alpha))$ which depends on the mechanism governing the reactive process, as shown by Equation (2):

$$
\frac{\mathrm{d} \alpha}{\mathrm{d} t}=k f(\alpha)
$$

where $k$ is the kinetic constant. If this constant is replaced by the Arrhenius equation, Equation (3) is obtained: 
$\frac{\mathrm{d} \alpha}{\mathrm{d} t}=k_{0} \exp \left(-\frac{E}{R T}\right) f(\alpha)$

where $k_{0}$ is the preexponential factor, $E$ activation energy, $R$ universal gas constant and $T$ temperature. By reordering the so-called temperature integral can be written as in Equation (4):

$g(\alpha)=\int_{0}^{\alpha} \frac{\mathrm{d} \alpha}{f(\alpha)}=\frac{k_{0}}{\beta} \int_{0}^{\mathrm{T}} \exp \left(-\frac{E}{R T}\right) \mathrm{d} T$

where $\beta$ is the heating rate $(\mathrm{d} T / \mathrm{d} t)$ and $g(\alpha)$ an integral function of the degree of conversion. Equation (4) may be integrated employing Doyle's approach [28] and rewritten in logarithm form as shown by Equation (5):

$\ln \beta=\ln \left[\frac{k_{0} E}{g(\alpha) R}\right]-5.330-\frac{1.0516 E}{R T}$

This equation enables to determine $E$ and the kinetic parameter $\ln \left[k_{0} E /(g(\alpha) R)\right]$ (Ozawa method [29]) for each degree of conversion. To determine the values of the preexponential factor for each degree of conversion the $R_{3}$ model (contracting volume mechanism) is applied. This kinetic model can be represented by its differential expression $f(\alpha)=$ $3(1-\alpha)^{2 / 3}$ and its integral expression $g(\alpha)=$ $1-(1-\alpha)^{1 / 3}$. This model has been previously determined for the resin/initiator system used in this work [30]. In this work it has been confirmed that the curing of PS-10/DGEBA formulations is also described by $R_{3}$ model.

In isothermal photocuring experiments the degree of conversion was calculated by Equation (6):

$\alpha=\frac{\Delta h_{\mathrm{t}}}{\Delta h_{\mathrm{ave}}}$

where $\Delta h_{\mathrm{t}}$ is the heat released up to a time $t$ and $\Delta h_{\text {ave }}$ is the average reaction heat obtained in the non-isothermal thermal curing (see Table 1). Equation (3) can also be used in the isothermal photocuring process and integrating this equation in isothermal conditions, Equation (7) is obtained [31]:

$\ln t=\ln \left[\frac{g(\alpha)}{k_{0}}\right]+\frac{E}{R T}$

which allows finding the activation energy for each degree of conversion from the slope of the linear relationship $\ln t$ vs. $1 / T$.
Table 1. Hydroxyl equivalents per epoxy equivalent (eq $\mathrm{OH} / \mathrm{ee}$ ) of DGEBA modified with different proportions of PS-10. Average total reaction heat $\left(\Delta h_{\mathrm{ave}}\right)$, kinetic constant at $160^{\circ} \mathrm{C}$ at a degree of conversion of $0.5\left(k_{160^{\circ} \mathrm{C}}\right)$ and experimental maximum glass transition temperature $\left(T_{\mathrm{g} \infty}\right)$ of the thermal curing of DGEBA modified with different proportions of PS-10. Experimental maximum glass transition temperature $\left(T_{\mathrm{g} \infty}\right)$ of the photocuring of DGEBA modified with different proportions of PS-10

\begin{tabular}{|c|c|c|c|r|c|}
\hline \multirow{2}{*}{$\%$ PS-10 } & \multirow{2}{*}{ eqOH/ee } & \multicolumn{3}{|c|}{ Thermal curing } & Photocuring \\
\cline { 3 - 6 } & $\begin{array}{c}\Delta \mathbf{h}_{\text {ave }} \\
{[\mathbf{k J} / \mathbf{e e}]}\end{array}$ & $\begin{array}{c}\mathbf{k}_{\mathbf{1 6 0}}{ }^{\circ} \mathbf{C} \\
{\left[\mathbf{s}^{-1}\right]}\end{array}$ & $\begin{array}{c}\mathbf{T}_{\mathbf{g} \infty} \\
{\left[{ }^{\circ} \mathbf{C}\right]}\end{array}$ & $\begin{array}{c}\mathbf{T}_{\mathbf{g} \infty} \\
{\left[{ }^{\circ} \mathbf{C}\right]}\end{array}$ \\
\hline 0 & 0.0545 & 99.6 & $6.46 \cdot 10^{-4}$ & 134 & 162 \\
\hline 5 & 0.0619 & 97.8 & $3.74 \cdot 10^{-4}$ & 101 & 135 \\
\hline 10 & 0.0692 & 99.1 & $2.07 \cdot 10^{-4}$ & 98 & 119 \\
\hline
\end{tabular}

In DGEBA modified with $10 \%$ of PS-10, as it has been commented in the experimental part, a dynamic post-curing (dark reaction) at different heating rates after photocuring the sample at $120^{\circ} \mathrm{C}$ has been made. The dynamic post-curing has also been studied by an isoconversional procedure using Equation (5) to find the activation energy and the preexponential factor, but these magnitudes have been found at different relative conversion degrees $\left(\alpha^{\prime}\right)$, see Equation (8):

$\alpha^{\prime}=\frac{\Delta h_{\mathrm{T}}}{\Delta h_{\mathrm{dyn}}}$

where in this case $\Delta h_{\mathrm{T}}$ is the heat released up to a temperature $T$ during the dynamic post-curing and $\Delta h_{\text {dyn }}$ the total reaction heat released during the dynamic post-curing part of the experiment.

\section{Results and discussion}

\subsection{Thermal curing}

Figure 2 shows the heat flow and the degree of conversion calculated using Equation (1) (see the inset in the figure) versus the temperature of neat DGEBA and DGEBA modified with 5 and $10 \%$ of PS-10, at a heating rate of $2.5^{\circ} \mathrm{C} / \mathrm{min}$. First of all, it must be noted that the curing process is complex, as detected by the presence of more than one peak in the thermograms and the changing slope in the conversion curves (see inset). On increasing the proportion of PS-10, the process broadens and extends to higher temperatures. However, the temperature of the first peak is hardly modified, while the second one moves towards higher temperatures on increasing 


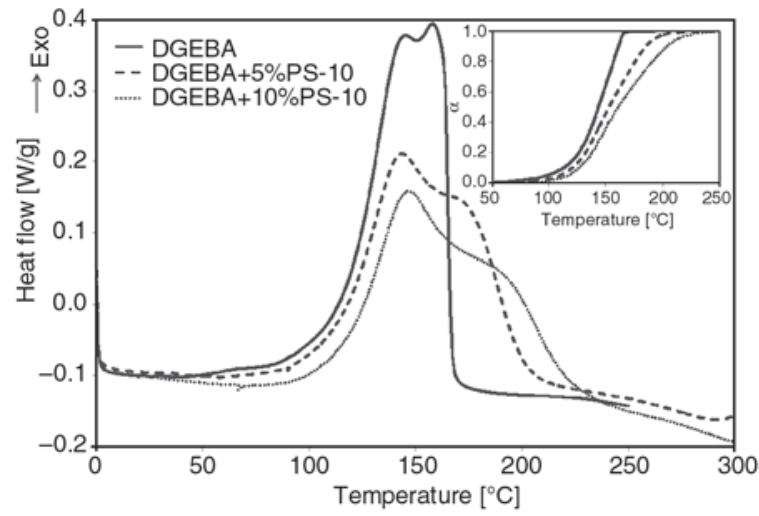

Figure 2. Heat flow and degree of conversion (as an inset) of the thermal curing at $2.5^{\circ} \mathrm{C} / \mathrm{min}$ of neat DGEBA and DGEBA modified with different proportions of PS-10

the proportion of PS-10 and it becomes a shoulder. This is also observed in the conversion curves as a progressive retardation as the degree of conversion increases. The presence of two peaks can be rationalized in terms of the competition between two different propagation mechanisms, the activated chainend (ACE) and the activated monomer (AM), which are described for cationic ring-opening polymerization. It is reported that the AM mechanism produces a proton-transfer reaction between a hydroxyl group and an activated epoxy group, which prevents subsequent chain growth and generates a new active species and growing chain, so a lower degree of crosslinking can be expected. In the absence of hydroxyl groups, the cationic epoxy curing only takes place via the ACE mechanism. In the ACE mechanism, propagation takes place through the reaction of epoxy groups with the active oxonium ion at the chain end [32]. In our case, the first peak can be related to AM mechanism and the second one with the ACE mechanism, since the first exotherm has a higher relative intensity than the second exotherm when hydroxyl content increases (see Table 1). Upon addition of a hydroxylic compound to the system, such as methanol, the first peak increases and this confirms that AM mechanism is the main process during this peak. As seen in Table 1, the number of hydroxyl groups increases with PS-10 proportion, then one would expect that the addition of PS-10 accelerated the thermal curing but the opposite effect is observed. The second curing exotherm, associated with the ACE propagation mechanism, is retarded due to the presence of PS10 , which suggests that PS-10 may participate in

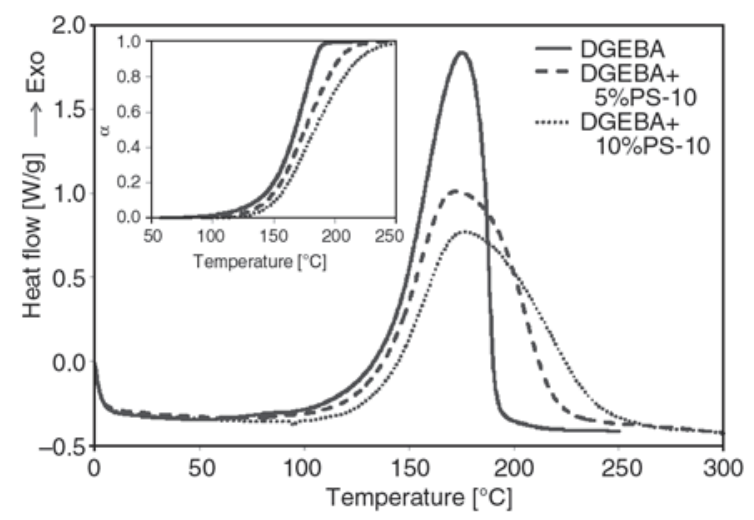

Figure 3. Heat flow and degree of conversion (as an inset) of the thermal curing at $10^{\circ} \mathrm{C} / \mathrm{min}$ of neat DGEBA and DGEBA modified with different proportions of PS-10

the curing process leading to either less mobile or less active propagating species.

At the other heating rates analyzed, the thermogram of the neat DGEBA only presents one peak (see Figure 3, corresponding to a heating rate of $10^{\circ} \mathrm{C} / \mathrm{min}$ ) and the thermograms of the modified systems present only a shoulder. Although two maxima cannot be observed, it is expected that both mechanisms, AM and ACE, compete in a similar way as observed at low heating rates. This can be clearly appreciated in the inset of Figure 3, where it is observed the same behaviour as at the lower heating rates.

Table 1 shows that the reaction heat of all formulations (in $\mathrm{kJee}^{-1}$ ), obtained as the average of the reaction heat at different heating rates, is almost the same and close to the reference value of $100 \mathrm{kJee}^{-1}$ for epoxy formulations [33]. This suggests that complete curing is reached for all formulations and that the presence of the multi-arm star polymer does not have any effect on the completion of the thermal cure.

Table 2 shows the results of the isoconversional analysis of the thermal curing of the different formulations, using Equation (5). In the neat DGEBA and the DGEBA modified with $5 \%$ of PS- 10 the activation energy increases with degree of conversion until $\alpha=0.9$, after which it remains fairly constant. When DGEBA is modified with $10 \%$ of PS- 10 the activation energy always increases with the degree of conversion. Until $\alpha=0.4$ the values of the activation energy for the different systems are very similar, but after this degree of conversion, the increase of activation energy with PS-10 proportion 
Table 2. Activation energy and pre-exponential factor of the thermal curing of DGEBA modified with different proportions of PS-10 at different degrees of conversion

\begin{tabular}{|c|c|c|c|c|c|c|c|c|c|c|c|c|}
\hline$\%$ PS-10 & & $\alpha=0.05$ & $\alpha=0.1$ & $\alpha=0.2$ & $\alpha=0.3$ & $\alpha=0.4$ & $\alpha=0.5$ & $\alpha=0.6$ & $\alpha=0.7$ & $\alpha=0.8$ & $\alpha=0.9$ & $\alpha=0.95$ \\
\hline \multirow{2}{*}{0} & $E[\mathrm{~kJ} / \mathrm{mo}$ & 74.8 & 79.7 & 83.7 & 85.5 & 86.9 & 88.4 & 91.0 & 94.5 & 97.8 & 99.6 & 98.6 \\
\hline & $k_{0}\left[\mathrm{~s}^{-1}\right]$ & $7.59 \cdot 10^{5}$ & $2.70 \cdot 10^{6}$ & $7.90 \cdot 10^{6}$ & $1.33 \cdot 10^{7}$ & $1.94 \cdot 10^{7}$ & $2.99 \cdot 10^{7}$ & $5.96 \cdot 10^{7}$ & $1.48 \cdot 10^{8}$ & $3.50 \cdot 10^{8}$ & $5.50 \cdot 10^{8}$ & $4.38 \cdot 10^{8}$ \\
\hline \multirow{2}{*}{5} & $E[\mathrm{~kJ} / \mathrm{mol}]$ & 79.4 & 81.8 & 85.4 & 87.9 & 91.1 & 96.7 & 104.9 & 114.6 & 123.6 & 130.0 & 129.7 \\
\hline & $k_{0}\left[\mathrm{~s}^{-1}\right]$ & $1.47 \cdot 10^{6}$ & $3.11 \cdot 10^{6}$ & $8.95 \cdot 10^{6}$ & $1.81 \cdot 10^{7}$ & $4.19 \cdot 10^{7}$ & $1.70 \cdot 10^{8}$ & $1.30 \cdot 10^{9}$ & $1.33 \cdot 10^{10}$ & $1.02 \cdot 10^{11}$ & $3.52 \cdot 10^{11}$ & $2.32 \cdot 10^{11}$ \\
\hline \multirow{2}{*}{10} & $E[\mathrm{~kJ} / \mathrm{mol}]$ & 76.5 & 81.6 & 86.2 & 89.0 & 93.3 & 101.6 & 115.1 & 132.9 & 152.4 & 170.4 & 182.7 \\
\hline & $k_{0}\left[\mathrm{~s}^{-1}\right]$ & $3.86 \cdot 10^{5}$ & $1.94 \cdot 10^{6}$ & $7.68 \cdot 10^{6}$ & $1.64 \cdot 10^{7}$ & $4.82 \cdot 10^{7}$ & $3.74 \cdot 10^{8}$ & $9.50 \cdot 10^{9}$ & $6.26 \cdot 10^{11}$ & $5.16 \cdot 10^{13}$ & $1.96 \cdot 10^{15}$ & $1.85 \cdot 10^{16}$ \\
\hline
\end{tabular}

is considerable. Activation energy is higher at higher star polymer content, in agreement with the decelerative effect of the modifier on the kinetics of thermal curing. The observed increase in activation energy during curing, which is more pronounced in formulations with $10 \%$ of PS- 10 , should be attributed to either a change in the curing mechanism by the participation of PS-10, leading to less active propagating species, or mobility restrictions occurring as a consequence of the participation of PS-10, rather than simply a change in the balance between the AM and ACE mechanisms due to the different hydroxyl content of the formulations.

In Table 2 the values of the preexponential factor using the $R_{3}$ model has also been reported. From the values of the activation energy and the preexponential factor the kinetic constant at $160^{\circ} \mathrm{C}$ and $\alpha=0.5$ has been calculated using the Arrhenius equation and these values are collected in Table 1. In agreement with the results presented in Figures 2 and 3, the kinetic constant decreases significantly on increasing the content in star polymer. These values are smaller than those found when a multiarm star poly(glycidol)-b-poly( $\varepsilon$-caprolactone) polymer was used as modifier [27]. It is hypothesized that the higher rigidity of the poly(styrene) core in comparison with the poly(glycidol) core can justify the observed differences between both modifiers, leading to more mobility restrictions caused by the participation of PS-10 in the curing process. However, on the basis of the results so far, in which PS-10 participates in a different way, the formation of a less active species should not be discarded.

In Table 1 the ultimate glass transition temperatures of the different systems are reported. The ultimate glass transition temperature is lower than the predicted by the Fox equation [34] and other common mixing rules. This indicates a strong modification of the structure of the epoxy matrix on samples thermally cured containing PS-10. Before curing, the star polymer has a compact structure due to the large number of intermolecular H-bonds and intramolecular H-bond interactions. These types of interactions decrease when the terminal hydroxyl groups react with the epoxy groups. The PS-10 molecules incorporated into the network increase the free volume and reduce considerably the crosslinking density and consequently the $T_{\mathrm{g}}$ of the cured materials, even below the $T_{\mathrm{g}}$ calculated with Fox equation and other common mixing rules. The difference between $T_{\mathrm{g} \infty}$ and the calculated $T_{\mathrm{g}}$ is much lower in the case of DGEBA modified with $10 \%$ of PS-10. Probably, this behaviour can be related to the fact that in some extent a part of $\mathrm{OH}$ groups in PS-10, in formulations containing a $10 \%$ of PS- 10 , are not completely covalently bonded to the epoxy matrix.

\subsection{Photocuring}

Figure 4 shows the heat flow and the degree of conversion (see inset) versus the photocuring time of DGEBA and DGEBA modified with different proportions of PS- 10 at $120^{\circ} \mathrm{C}$. Although the modified systems have a higher proportion of photoinitiator, PS-10 produces a strong deceleration of the photocuring process. In the case of neat DGEBA, vitri-

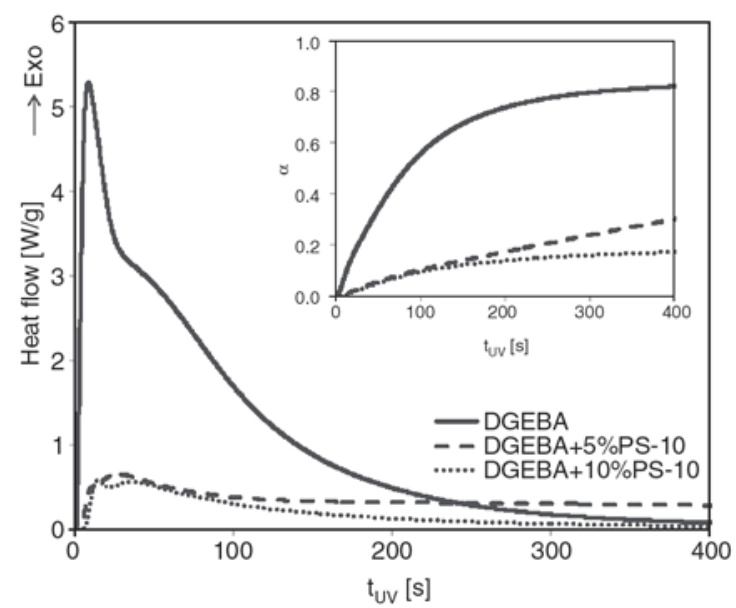

Figure 4. Heat flow and degree of conversion (as an inset) of the photocuring process of neat DGEBA and DGEBA modified with different proportions of PS- 10 at $120^{\circ} \mathrm{C}$ 
Table 3. Values of $\Delta h_{\text {iso }}$ in $\mathrm{kJ} / \mathrm{ee}$ for the photocuring of DGEBA modified with different proportions of PS-10 and temperatures

\begin{tabular}{|c|c|c|c|c|c|}
\hline $\mathbf{\%}$ PS-10 & $\mathbf{4 0}^{\circ} \mathbf{C}$ & $\mathbf{6 0}^{\circ} \mathbf{C}$ & $\mathbf{8 0}^{\circ} \mathbf{C}$ & $\mathbf{1 0 0}^{\circ} \mathbf{C}$ & $\mathbf{1 2 0}^{\circ} \mathbf{C}$ \\
\hline 0 & 55.3 & 67.3 & 75.5 & 80.8 & 85.3 \\
\hline 5 & 46.3 & 66.0 & 74.2 & 75.3 & 75.9 \\
\hline 10 & & & & & 19.4 \\
\hline
\end{tabular}

Table 4. Values of $\alpha_{\text {iso }}$ for the photocuring of DGEBA modified with different proportions of PS-10 and temperatures

\begin{tabular}{|c|c|c|c|c|c|}
\hline \% PS-10 & $\mathbf{4 0}^{\circ} \mathbf{C}$ & $\mathbf{6 0}^{\circ} \mathbf{C}$ & $\mathbf{8 0}^{\circ} \mathbf{C}$ & $\mathbf{1 0 0}^{\circ} \mathbf{C}$ & $\mathbf{1 2 0}^{\circ} \mathbf{C}$ \\
\hline 0 & 0.555 & 0.676 & 0.758 & 0.811 & 0.856 \\
\hline 5 & 0.473 & 0.674 & 0.759 & 0.770 & 0.776 \\
\hline 10 & & & & & 0.196 \\
\hline
\end{tabular}

fication was achieved at the end of the $30 \mathrm{~min}$ of irradiation time. However, in the case of DGEBA with $5 \%$ of PS- 10 , the photocuring process needed to be extended to longer irradiation times (see Figure 4), as described in the experimental section, in order to reach vitrification. As can be seen in Tables 3 and 4 , the values of $\Delta h_{\text {iso }}$ (isothermal curing heat) and $\alpha_{\text {iso }}$ (degree of conversion after the photocuring experiment) are only slightly lower than the attained ones when the formulation is the neat DGEBA. The photocuring process practically ends at the same time in the case of neat formulation and DGEBA modified with $10 \%$ of PS-10, as it can be appreciated from the inset of Figure 4. But, as observed in Tables 3 and 4, the values of $\Delta h_{\text {iso }}$ and $\alpha_{\text {iso }}$ for the modified system at $120^{\circ} \mathrm{C}$ are much smaller than the corresponding to neat DGEBA. The heat of reaction is very low for temperatures below $120^{\circ} \mathrm{C}$ for DGEBA modified with $10 \%$ of PS-10 which indicates that the formulations with $10 \%$ of PS- 10 hardly react even at high temperatures, whereas photocuring of neat DGEBA is near complete and only restricted by vitrification. For all these reasons the photocuring process of DGEBA modified with $5 \%$ of PS- 10 has been analyzed as in the case of neat DGEBA. On the other hand, in the case of DGEBA with $10 \%$ of PS-10 the kinetics of the photocuring process has not been studied due to the low value of the heat involved in the photocur-

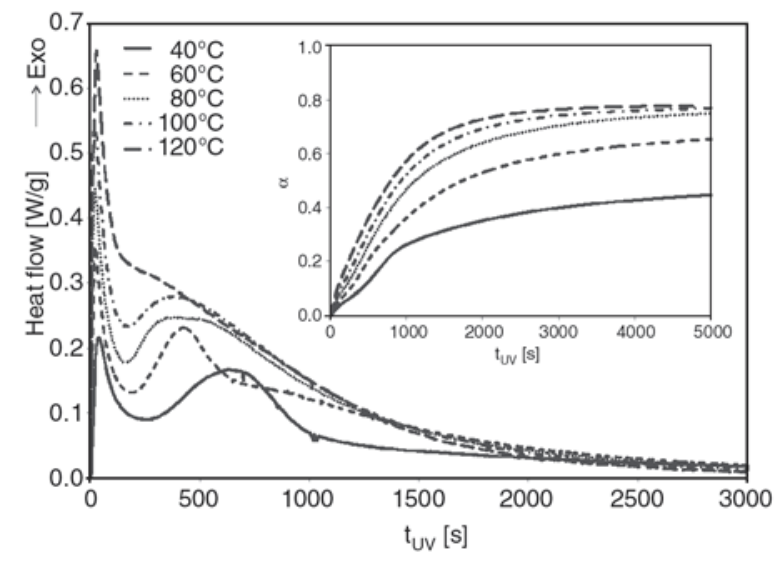

Figure 5. Heat flow and degree of conversion (as an inset) of the photocuring process of DGEBA modified with $5 \%$ of PS-10 at different temperatures

ing and only the kinetics of a subsequent thermal post-curing has been analyzed instead.

Figure 5 shows the heat flow and the degree of conversion (see inset) versus the photocuring time of DGEBA with 5\% of PS-10 at different temperatures. As usually reported for other photocuring systems [35], at the beginning of the process the heat flow and the degree of conversion increase with temperature. At the lower temperatures two peaks appear, probably related to the existence of two propagation mechanisms, AM and ACE. The time corresponding to the second peak decreases on increasing the temperature. At $120^{\circ} \mathrm{C}$ this second peak disappears and it becomes a shoulder of the mean peak.

The kinetics of the photocuring process for neat DGEBA and DGEBA with $5 \%$ of PS-10 between 80 and $120^{\circ} \mathrm{C}$ has been analyzed using the isoconversional methodology explained above. Using Equation (7), the activation energy for every degree of conversion has been found. The results are collected in Table 5. While for neat DGEBA formulation the activation energy increases with the degree of conversion, when a 5\% of PS-10 is added the activation energy fluctuates, reaching slightly different values than the neat formulation. The different behaviour in the curing of both formulations can be explained by the complex influence of the timedependent irradiation and subsequent photoinitia-

Table 5. Activation energy of the photocuring of DGEBA and DGEBA modified with 5\% of PS-10 at different degrees of conversion

\begin{tabular}{|c|c|c|c|c|c|c|c|}
\hline \% PS-10 & $\boldsymbol{\alpha}=\mathbf{0 . 0 5}$ & $\boldsymbol{\alpha}=\mathbf{0 . 1}$ & $\boldsymbol{\alpha}=\mathbf{0 . 2}$ & $\boldsymbol{\alpha}=\mathbf{0 . 3}$ & $\boldsymbol{\alpha}=\mathbf{0 . 4}$ & $\boldsymbol{\alpha}=\mathbf{0 . 5}$ & $\boldsymbol{\alpha}=\mathbf{0 . 6}$ \\
\hline 0 & 8.3 & 8.1 & 10.3 & 14.0 & 15.9 & 16.8 & 17.3 \\
\hline 5 & 12.4 & 18.5 & 13.9 & 10.9 & 9.5 & 9.7 & 11.7 \\
\hline
\end{tabular}


tion in the photocuring process, which is not, in consequence, only a temperature-dependent process [36]. It can also be hypothesized that the presence of PS-10 may interfere with the curing process, resulting in the formation of different active species, as discussed below. The competition between AM and ACE mechanism and the different protogenic nature of the reaction medium can also help to explain the observed differences [37].

Figures 6 and 7 show the heat flow of the dynamic postcuring experiment of neat DGEBA and the formulation with $5 \%$ of PS-10, respectively, made after the photocuring experiences at the temperatures indicated. In the case of neat DGEBA (Figure 6), it can be observed that the post-curing process begins at temperatures above the temperature of isothermal photocuring and shows two maxima that appear at the lower temperatures $(40,60$ and $80^{\circ} \mathrm{C}$ ). The height of the first one decreases on increasing the curing temperature. At $100^{\circ} \mathrm{C}$ this first peak becomes a shoulder and at $120^{\circ} \mathrm{C}$ this shoulder completely disappears. The height of the

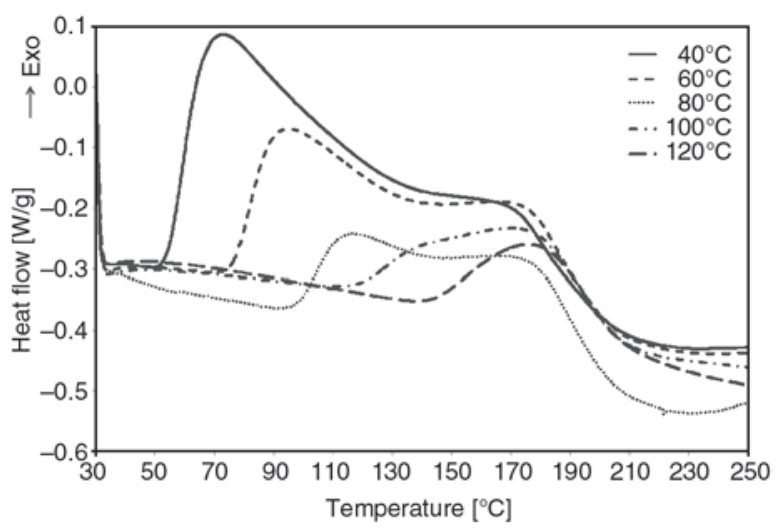

Figure 6. Dynamic postcuring of neat DGEBA after photocuring process at different temperatures

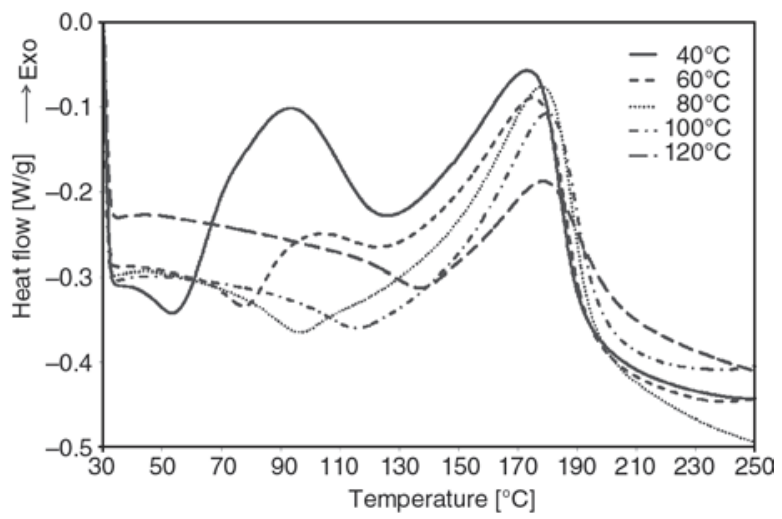

Figure 7. Dynamic postcuring of DGEBA modified with $5 \%$ of PS-10 after photocuring process at different temperatures second peak hardly varies, because its temperature is higher than that of the photocuring process. The first exotherm, which starts at a temperature close to the photocuring temperature [38], can be associated with the propagation of active species formed during photocuring and entrapped in the vitrified material, and the second one with the propagation of less mobile species after structural relaxation of the network [39] or reactivation of dormant tertiary oxonium cations by increasing the temperature [32]. When DGEBA is modified with $5 \%$ of PS- 10 , a glass transition is clearly observed before the onset of the first exothermic peak, which is displaced towards higher temperatures when photocuring temperature increases (Figure 7). At the lower temperatures $\left(40\right.$ and $\left.60^{\circ} \mathrm{C}\right)$ two peaks appear. The first one becomes a shoulder at $80^{\circ} \mathrm{C}$ and at higher temperatures it disappears. The height of the second peak decreases on increasing the temperature. With the exception of the curve registered after a photocuring at $40^{\circ} \mathrm{C}$, the size of the second peak is always larger than that of the first peak. However, in the case of neat DGEBA, the size of the first peak is higher than the second peak at the lower temperatures (see Figure 6). Although the nature of two peaks in 5\% of PS-10 formulation is expected to be the same as in the neat formulation, the high intensity of the second peak for all photocuring temperatures suggests the formation of a dormant species during photocuring, which can be reactivated when the temperature increases (during second peak). It was previously described that the presence of nitrogen in the chemical structure of the epoxy monomers prevents photopolymerization or photocrosslinking reaction to occur. The degree of retardation depends both on the amount and basicity of the amine concerned [40]. Thus, the presence of nitrogen in the structure of stars could be the reason for the inactivation of the photocuring process, because nitrogen atoms in the form of tertiary amine can interact with the protons generated by the irradiation on the photocuring initiator, producing ammonium salts, because of their basic character. However, it should be commented that the study was done with monomers containing nitrogen in the structure, which leads to a high proportion of this heteroatom in the mixtures and no reactivation by heating of the sample was tested. Endo and Sanda [41] reported that benzyl ammonium salts can act as latent thermal initiators. Thus, it seems reasonable that the inacti- 
vation of the photocuring process by the presence of benzylic amine moieties in the multiarm star structure can be followed by the reactivation at high temperature by the breakage of the benzylic ammonium salt. This breakage produces benzylic cations capable of initiating the thermal cationic polymerization of epoxides. The low nucleophilicity of the anion, hexafluoroantimonate, helps to increase the reactivity of these species.

The in situ generation of a thermal initiator by a photoirradiation process by addition of the PS- 10 stars to the epoxy formulation opens the way to a new dual curing system, related to another previously described [42]. In that case, the responsible of the dual behaviour was the presence of a hyperbranched modifier in the formulation with thioether as repeating unit, which can be transformed into alkyl sulfonium species upon photolysis of the photoinitiator. Sulfonium cations can also act as cationic thermal latent initiators. However, the structure of the hyperbranched modifier with a huge proportion of thioether groups in the modifier structure led to a higher functionality as macroinitiator, which is not the case of the star structures, having an only benzylamine group per arm.

Figure 8 shows the heat flow and the relative conversion degree (as an inset) of the postcuring scan at different heating rates, made after photocuring samples of DGEBA with $10 \%$ of PS-10 at $120^{\circ} \mathrm{C}$

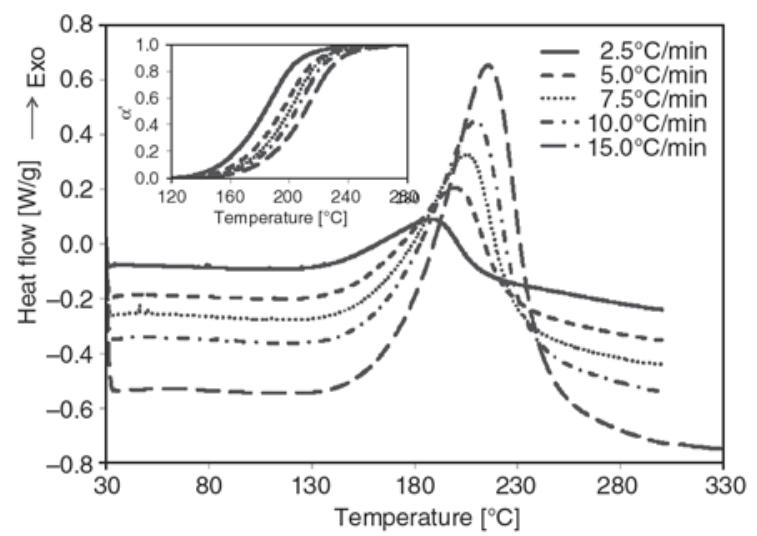

Figure 8. Dynamic postcuring (after UV irradiation) at different heating rates and relative conversion degree (as an inset) of DGEBA modified with $10 \%$ of PS-10 for $30 \mathrm{~min}$. It can be observed that only one strong peak appears at high temperature. When the same formulation was thermally cured without previous UV-irradiation, the thermogram did not show any exotherm. These results suggest, as it had been hypothesized, that in presence of PS-10, UV irradiation promotes the formation of a thermal macroinitiator (dormant species), by reaction between the amine groups of PS-10 and the proton resulting from the photolysis of the photoinitiator upon irradiation, which can be subsequently activated by heating. However, this curing system shows a small latency since the slope of the stimulation-activity curve is small (see inset in Figure 8) [41].

Table 6 shows the results of the isoconversional analysis based on DSC thermograms of Figure 8. Using Equation (5), the activation energy has been found for some values of relative conversion degrees. This magnitude first decreases, but after $\alpha^{\prime}=0.2$ it increases. The high activation energy values obtained in comparison with those obtained during photocuring (Table 5) suggests again the formation of dormant species during UV irradiation which can act as thermal initiator upon heating. In the same table the values of the preexponential factor using $R_{3}$ model are also collected.

Table 1 shows the $T_{\mathrm{g} \infty}$ of DGEBA with 5\% of PS- 10 . These values are lower than those calculated using common mixing rules, indicating a modification of the structure of the epoxy matrix. However, the difference between $T_{\mathrm{g} \infty}$ and the calculated $T_{\mathrm{g}}$ is smaller than in the case of the thermal curing. As it has been stated, the number of intermolecular and intramolecular H-bond interactions and the degree of chemical incorporation of PS-10 to the epoxy matrix, can justify the differences between the experimental and calculated $T_{\mathrm{g} \infty}$. The value of the $T_{\mathrm{g} \infty}$ of DGEBA with $10 \%$ of PS-10 is also smaller than the calculated ones, indicating a structural modification of the epoxy matrix. In fact, the breakage of the star structure by formation of benzylic cations should lead to the separation of the arms from the hyperbranched core. This process can occur to some extent, but should produce a plasticization of the matrix that counteracts the effect of the multifunc-

Table 6. Activation energy and pre-exponential factor of the thermal curing of DGEBA modified with $10 \%$ of PS-10 after photocuring at $120^{\circ} \mathrm{C}$ at different relative conversion degrees

\begin{tabular}{|l|c|c|c|c|c|c|c|c|c|c|c|}
\hline & $\boldsymbol{\alpha}^{\prime}=\mathbf{0 . 0 5}$ & $\boldsymbol{\alpha}^{\prime}=\mathbf{0 . 1}$ & $\boldsymbol{\alpha}^{\prime}=\mathbf{0 . 2}$ & $\boldsymbol{\alpha}^{\prime}=\mathbf{0 . 3}$ & $\boldsymbol{\alpha}^{\prime}=\mathbf{0 . 4}$ & $\boldsymbol{\alpha}^{\prime}=\mathbf{0 . 5}$ & $\boldsymbol{\alpha}^{\prime}=\mathbf{0 . 6}$ & $\boldsymbol{\alpha}^{\prime}=\mathbf{0 . 7}$ & $\boldsymbol{\alpha}^{\prime}=\mathbf{0 . 8}$ & $\boldsymbol{\alpha}^{\prime}=\mathbf{0 . 9}$ & $\boldsymbol{\alpha}^{\prime}=\mathbf{0 . 9 5}$ \\
\hline$E[\mathrm{~kJ} / \mathrm{mol}]$ & 119.4 & 114.8 & 112.9 & 114.3 & 117.0 & 120.0 & 123.2 & 126.4 & 130.5 & 139.1 & 148.1 \\
\hline$k_{0}\left[\mathrm{~s}^{-1}\right]$ & $1.45 \cdot 10^{10}$ & $4.07 \cdot 10^{9}$ & $2.25 \cdot 10^{9}$ & $2.91 \cdot 10^{9}$ & $5.32 \cdot 10^{9}$ & $1.06 \cdot 10^{10}$ & $2.15 \cdot 10^{10}$ & $4.32 \cdot 10^{10}$ & $1.00 \cdot 10^{11}$ & $5.44 \cdot 10^{11}$ & $2.61 \cdot 10^{12}$ \\
\hline
\end{tabular}


tional character of the benzylic hyperbranched initiator formed. Although the reason of this behaviour can be rationalized in a similar way to $5 \%$ PS- 10 formulation, the fact that some part of PS-10 phase separates during curing, (as it will be seen later by scanning electron microscopy) can probably have an influence on the $T_{\mathrm{g} \infty}$ value. The values of $T_{\mathrm{g} \infty}$ found after photocuring are higher than those found after thermal curing (Table 1), because ytterbium triflates are able to induce reorganization, cyclization and/or degradation reactions when the curing reaches too high temperatures, which results in a network structure with a lower degree of crosslinking and consequently with a lower $T_{\mathrm{g} \infty}[43,44]$.

\subsection{Fracture morphology by SEM}

The topography of photocured and postcured samples of neat DGEBA and DGEBA with $10 \%$ of PS10 have been investigated by SEM. The microphotographs of the facture surface are collected in Figure 9 and 10, respectively. The existence of an only homogeneous phase in the neat DGEBA and the presence of two phases in DGEBA with $10 \%$ of PS-10 can be observed. This material shows a rougher appearance than the neat formulation, based on rod-like particles with a size of ca 50 $500 \mathrm{~nm}$ homogeneously dispersed. It is worth to state that thermally cured samples do not show evidences of a second phase. So, it is expected that PS10 modifier can improve the fracture properties of DGEBA by a phase-separation mechanism, only when the material is previously UV irradiated.

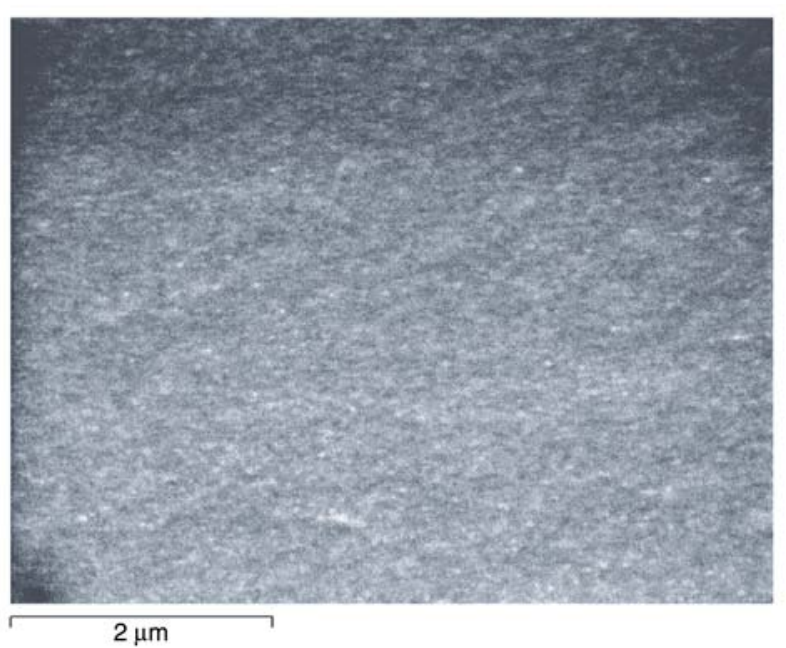

Figure 9. Surface morphology obtained by SEM of neat DGEBA

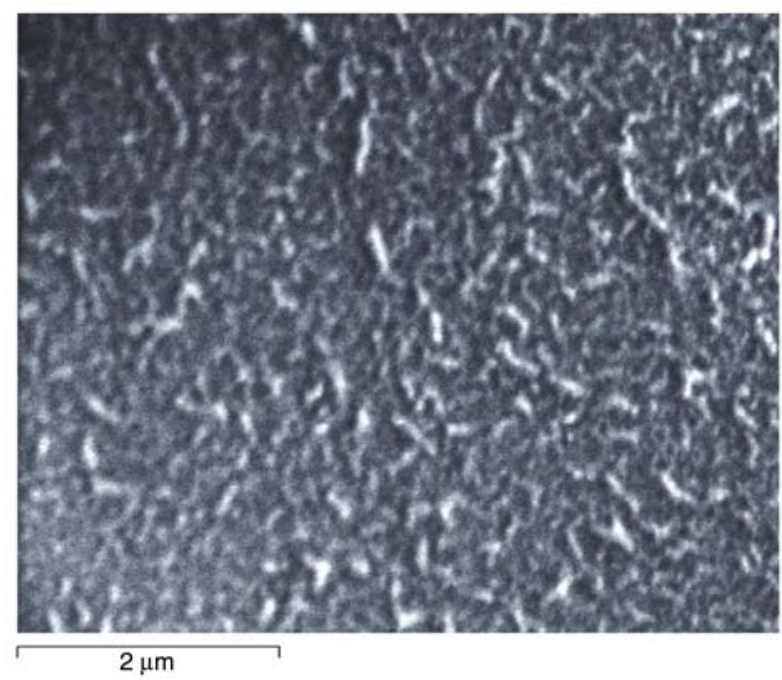

Figure 10. Surface morphology obtained by SEM of DGEBA modified with $10 \%$ of PS-10

\section{Conclusions}

PS-10 decelerates the thermal curing of DGEBA, modifying significantly the structure of the epoxy matrix in terms of ultimate glass transition temperature. PS-10 also decelerates the photocuring process of DGEBA but in a different way. With a $5 \%$ of PS10 , the process is significantly delayed but can proceed to vitrification, as in modified DGEBA. With a $10 \%$ of PS-10 the photocuring is strongly limited and it is necessary a subsequent thermal curing to reticulate the sample. The decelerating effect on the photocuring process is explained in terms of the formation of dormant species by protonation of the amine groups in the multiarm star molecule. The benzylic ammonium salts formed are reactivated upon heating, thus acting as a thermal initiator. Thus the addition of PS-10 to the epoxy formulation leads to a new dual photo-thermal curing system. Upon irradiation a benzylic cationic multifunctional initiator is formed, which can act a thermal curing system. In the photocuring process the addition of PS-10 also modifies the structure of the epoxy matrix, but in a lower extent than in the thermal curing.

Depending on the initiation conditions, thermal or UV induced, and on the amount of PS-10 it is possible to obtain tailor-made thermosets with different thermal and mechanical properties and morphology. The resulting morphology of DGEBA/PS-10 formulations UV-cured is that of nanosize 'rod-like' of homogeneously dispersed particles in the epoxy matrix, with a potential capacity of increasing toughness of UV-cured DGEBA thermosets. 


\section{Acknowledgements}

The authors would like to thank MICINN (Ministerio de Ciencia e Innovación) and FEDER (Fondo Europeo de Desarrollo Regional) (MAT2011-27039-C03-01 and MAT2011-27039-C03-02) and to the Comissionat per a Universitats i Recerca del DIUE de la Generalitat de Catalunya (2009-SGR-1512). M.M. acknowledges the grant FIDGR (2009) from the Catalonian Government. X.F.F. acknowledges the grant JCI-2010-06187 from the Spanish Government.

\section{References}

[1] May C. A.: Introduction to epoxy resins. in 'Epoxy resins. Chemistry and technology’ (ed.: May C. A.) Marcel Dekker, New York 1-8 (1988).

[2] Petrie E. M.: Epoxy adhesive formulations. McGrawHill, New York (2006).

[3] Pascault J. P., Williams R. J. J.: Epoxy polymers: New materials and innovations. Wiley-VCH, Weinheim (2010).

[4] Kinloch A. J., Shaw S. J., Tod D. A., Hunston D. L.: Deformation and fracture behaviour of a rubber-toughened epoxy: 1. Microstructure and fracture studies. Polymer, 24, 1341-1354 (1983). DOI: 10.1016/0032-3861(83)90070-8

[5] Ho T-H., Wang C-S.: Toughening of epoxy resins by modification with dispersed acrylate rubber for electronic packaging. Journal of Applied Polymer Science, 50, 477-483 (1993). DOI: 10.1002/app.1993.070500311

[6] Mezzenga R., Boogh L., Månson J-A. E.: A review of dendritic hyperbranched polymer as modifiers in epoxy composites. Composites Science and Technology, 61, 787-795 (2001). DOI: $10.1016 / \mathrm{S} 0266-3538(01) 00022-7$

[7] Guo Q., Habrard A., Park Y., Halley P. J., Simon G. P.: Phase separation, porous structure, and cure kinetics in aliphatic epoxy resin containing hyperbranched polyester. Journal of Polymer Science Part B: Polymer Physics, 44, 889-899 (2006).

DOI: 10.1002/polb.20757

[8] Ratna D., Varley R., Simon G. P.: Toughening of trifunctional epoxy using an epoxy-functionalized hyperbranched polymer. Journal of Applied Polymer Science, 89, 2339-2345 (2003).

DOI: 10.1002/app.12059

[9] He S., Shi K., Bai J., Zhang Z., Li L., Du Z., Zhang B.: Studies on the properties of epoxy resins modified with chain-extended ureas. Polymer, 42, 9641-9647 (2001). DOI: 10.1016/S0032-3861(01)00450-5

[10] Evans D., Canfer S. J.: Radiation stable, low viscosity impregnating resin systems for cryogenic applications. Advances in Cryogenic Engineering Materials, 46, 361-368 (2000). DOI: $10.1007 / 978-1-4615-4293-346$

[11] Ueki T., Nishijima S., Izumi Y.: Designing of epoxy resin systems for cryogenic use. Cryogenics, 45, 141148 (2005). DOI: $10.1016 / \mathrm{j}$. cryogenics.2004.07.002
[12] Nishijima S., Honda Y., Okada T.: Application of the positron annihilation method for evaluation of organic materials for cryogenic use. Cryogenics, 35, 779-781 (1995). DOI: 10.1016/0011-2275(95)90913-Z

[13] Morell M., Ramis X., Ferrando F., Serra A.: Effect of polymer topology on the curing process and mechanical characteristics of epoxy thermosets modified with linear or multiarm star poly( $\varepsilon$-caprolactone). Polymer, 52, 4694-4702 (2011).

DOI: $10.1016 /$ j.polymer.2011.07.040

[14] Riew C. K., Siebert A. R., Smith R. W., Fernando M., Kinloch A. J.: Toughened epoxy resins: Preformed particles as tougheners for adhesives and matrices. in: 'Toughened plastics II' (eds.: Riew C. K., Kinloch A. J.) American Chemical Society, Washington, Advances in Chemical Series Vol 252, 33-44 (1996).

DOI: $10.1021 / \mathrm{ba}-1996-0252 . \mathrm{ch} 003$

[15] Wu S.: Phase structure and adhesion in polymer blends: A criterion for rubber toughening. Polymer, 26, 18551863 (1985).

DOI: 10.1016/0032-3861(85)90015-1

[16] Pearson R. A., Yee A. F.: Toughening mechanisms in thermoplastic-modified epoxies: 1. Modification using poly(phenylene oxide). Polymer, 34, 3658-3670 (1993). DOI: 10.1016/0032-3861(93)90051-B

[17] Hedrick J. L., Yilgor I., Jurek M., Hedrick J. C., Wilkes G. L., McGrath J. E.: Chemical modification of matrix resin networks with engineering thermoplastics: 1 . Synthesis, morphology, physical behaviour and toughening mechanisms of poly(arylene ether sulphone) modified epoxy networks. Polymer, 32, 20202032 (1991).

DOI: 10.1016/0032-3861(91)90168-I

[18] Wilkinson S. P., Ward T. C., McGrath J. E.: Effect of thermoplastic modifier variables on toughening a bismaleimide matrix resin for high-performance composite materials. Polymer, 34, 870-884 (1993).

DOI: 10.1016/0032-3861(93)90376-L

[19] Kunz S. C., Sayre J. A., Assink R. A.: Morphology and toughness characterization of epoxy resins modified with amine and carboxyl terminated rubbers. Polymer, 23, 1897-1906 (1982). DOI: 10.1016/0032-3861(82)90215-4

[20] Voit B.: New developments in hyperbranched polymers. Journal of Polymer Science Part A: Polymer Chemistry, 38, 2505-2525 (2000).

DOI: 10.1002/1099-0518(20000715)38:14<2505::AIDPOLA $10>3.0 . C O ; 2-8$

[21] Sörensen K., Pettersson B. O., Boogh L., Månson J-A. E.: Dendritic polyester macromolecule in thermosetting resin matrix. PCT Patent SE94/04440, Sweden (1994).

[22] Zhang Y., Zhang D., Qin C., Xu J.: Physical and mechanical properties of dental nanocomposites composed of aliphatic epoxy resin and epoxidized aromatic hyperbranched polymers. Polymer Composites, 30, 176-181 (2009).

DOI: $10.1002 /$ pc.20549 
[23] Fernández-Francos X., Salla J. M., Cadenato A., Morancho J. M., Serra A., Mantecón A., Ramis X.: A new strategy for controlling shrinkage of DGEBA resins cured by cationic copolymerization with hydroxyl-terminated hyperbranched polymers and ytterbium triflate as an initiator. Journal of Applied Polymer Science, 111, 2822-2829 (2009).

DOI: $10.1002 /$ app.29317

[24] Morancho J. M., Cadenato A., Ramis X., FernándezFrancos X., Salla J. M.: Thermal curing and photocuring of an epoxy resin modified with a hyperbranched polymer. Thermochimica Acta, 510, 1-8 (2010). DOI: $10.1016 /$ j.tca.2010.05.008

[25] Morancho J. M., Cadenato A., Ramis X., FernándezFrancos X., Flores M., Salla J. M.: Effect of a hyperbranched polymer over the thermal curing and the photocuring of an epoxy resin. Journal of Thermal Analysis and Calorimetry, 105, 479-488 (2011).

DOI: $10.1007 / \mathrm{s} 10973-010-1277-8$

[26] Morell M., Foix D., Lederer A., Ramis X., Voit B., Serra A.: Synthesis of a new multiarm star polymer based on hyperbranched poly(styrene) core and poly ( $\varepsilon$-caprolactone) arms and its use as reactive modifier of epoxy thermosets. Journal of Polymer Science Part A: Polymer Chemistry, 49, 4639-4649 (2011). DOI: $10.1002 /$ pola.24908

[27] Morancho J. M., Cadenato A., Ramis X., Morell M., Fernández-Francos X., Salla J. M., Serra À.: Thermal curing and photocuring of a DGEBA modified with multiarm star poly(glycidol)- $b$-poly( $\varepsilon$-caprolactone) polymers of different arm lengths. Journal of Thermal Analysis and Calorimetry, in press (2013).

DOI: $10.1007 / \mathrm{s} 10973-012-2919-9$

[28] Doyle C. D.: Series approximations to the equation of thermogravimetric data. Nature, 207, 290-291 (1965). DOI: $10.1038 / 207290 \mathrm{a} 0$

[29] Ozawa T.: A new method of analyzing thermogravimetric data. Bulletin of the Chemical Society of Japan, 38, 1881-1886 (1965).

DOI: $10.1246 /$ bcsj. 38.1881

[30] González S., Fernández-Francos X., Salla J. M., Serra A., Mantecón A., Ramis X.: New thermosets obtained by cationic copolymerization of DGEBA with $\gamma$-caprolactone with improvement in the shrinkage. II. Timetemperature-transformation (TTT) cure diagram. Journal of Applied Polymer Science, 104, 3406-3416 (2007). DOI: $10.1002 / a p p .26021$

[31] Morancho J. M., Cadenato A., Fernández-Francos X., Salla J. M., Ramis X.: Isothermal kinetics of photopolymerization and thermal polymerization of bisGMA/TEGDMA resins. Journal of Thermal Analysis and Calorimetry, 92, 513-522 (2008).

DOI: $10.1007 / \mathrm{s} 10973-007-8432-\mathrm{x}$

[32] Matějka L., Chabanne P., Tighzert L., Pascault J. P.: Cationic polymerization of diglycidyl ether of bisphenol A. Journal of Polymer Science Part A: Polymer Chemistry, 32, 1447-1458 (1994).

DOI: $10.1002 /$ pola.1994.080320806
[33] Leonard J.: Heats and entropies of polymerization, ceiling temperatures, equilibrium monomer concentrations, and polymerizability of heterocyclic compounds. in 'Polymer handbook' (eds.: Brandrup J., Immermut E. H., Grulke E. A.), Wiley-Interscience, New York, Vol 1, II/363-II/414 (1999).

[34] Wood L. A.: Glass transition temperatures of copolymers. Journal of Polymer Science, 28, 319-330 (1958). DOI: $10.1002 /$ pol.1958.1202811707

[35] Fernández-Francos X., Salla J. M., Cadenato A., Morancho J. M., Mantecón A., Serra A., Ramis X.: Influence of the initiating mechanism on the cationic photopolymerization of a cycloaliphatic epoxy resin with arylsulfonium salts. Journal of Polymer Science Part A: Polymer Chemistry, 45, 16-25 (2007). DOI: $10.1002 /$ pola. 21811

[36] Tryson G. R., Shultz A. R.: A calorimetric study of acrylate photopolymerization. Journal of Polymer Science: Polymer Physics Edition, 17, 2059-2075 (1979). DOI: $10.1002 /$ pol.1979.180171202

[37] Crivello J. V., Bulut U.: Dual photo- and thermally initiated cationic polymerization of epoxy monomers. Journal of Polymer Science Part A: Polymer Chemistry, 44, 6750-6764 (2006).

DOI: $10.1002 /$ pola.21791

[38] Scott T. F., Cook W. D., Forsythe J. S.: Photo-DSC cure kinetics of vinyl ester resins. I. Influence of temperature. Polymer, 43, 5839-5845 (2002). DOI: $10.1016 / \mathrm{S} 0032-3861(02) 00490-1$

[39] Chen Z., Webster D. C.: Study of the effect of hyperbranched polyols on cationic UV curable coating properties. Polymer International, 56, 754-763 (2007). DOI: $10.1002 /$ pi.2202

[40] Rath S. K., Diby A., Seghier Z., Boey F. Y. C., Abadie M. J. M.: The effect of amines on the UV-curing of epoxy resins. Iranian Polymer Journal, 15, 855-862 (2006).

[41] Endo T., Sanda F.: Design of latent catalysts and their application to polymer synthesis. Macromolecular Symposia, 107, 237-242 (1996).

DOI: $10.1002 /$ masy. 19961070123

[42] Foix D., Ramis X., Serra A., Sangermano M.: UV generation of a multifunctional hyperbranched thermal crosslinker to cure epoxy resins. Polymer, 52, 32693276 (2011).

DOI: 10.1016/j.polymer.2011.05.029

[43] Fernández-Francos X., Salla J. M., Pérez G., Mantecón A., Serra À., Ramis X.: New thermosets obtained by thermal and UV-induced cationic copolymerization of DGEBA with 4-phenyl- $\gamma$-butyrolactone. Macromolecular Chemistry and Physics, 210, 1450-1460 (2009).

DOI: $10.1002 / \mathrm{macp} .200900118$

[44] Aspinall H. C., Dwyer J. L. M., Greeves N., McIver E. G., Woolley J. C.: Solubilized lanthanide triflates: Lewis acid catalysis by polyether and poly(ethylene glycol) complexes of $\operatorname{Ln}(\mathrm{OTf})_{3}$. Organometallics, 17, 1884-1888 (1998).

DOI: $10.1021 / \mathrm{om} 9709087$ 